\title{
Eficácia da Profilaxia Antibiótica na Terapêutica Odontológica: Revisão Sistematizada
} Effectiveness of Antibiotic Prophylaxis in Dental Therapeutics: Systematic Review Eficacia de la Profilaxis de Antibióticos en Terapéutica Dental: Revisión Sistemática

Matheus Andrade RODRIGUES Graduando do curso de Odontologia. Departamento de Odontologia. Universidade Estadual da Paraíba. Campus VIII, 58.233-000 Araruna - $P B$, Brasil https://orcid.org/0000-0003-2501-6546

Matheus Harllen Gonçalves VERÍSSIMO Graduando do curso de Odontologia. Departamento de Odontologia. Universidade Estadual da Paraíba. Campus VIII 58.233-000 Araruna - PB, Brasil https://orcid.org/0000-0003-2845-4832 Jéssica Fernanda Delfino dos SANTOS Cirurgiã-Dentista pela Universidade Federal de Campina Grande. Residente em Atenção primária à saúde (Núcleo de Odontologia) pelo Centro Universitário de Patos, 58704-000 Patos - PB, Brasil https://orcid.org/0000-0003-3064-642X Gustavo Correia Basto da SILVA

Professor do Curso de Odontologia. Doutorando em Odontologia pela UEPB. Departamento de Odontologia. Universidade Estadual da Paraíba. Campus VIII - 58.233-000 Araruna-PB, Brasil https://orcid.org/0000-0002-6081-2540

\section{Resumo}

Introdução: o envolvimento bacteriano constitui uma das principais causas de infecções na região de cabeça e pescoço. Por esse motivo, a abordagem terapêutica com antimicrobianos é recorrente na área da Odontologia, assim como é bastante comum o uso dessas drogas como mecanismo terapêutico profilático no combate a possíveis infecções sistêmicas no pré e pós-operatório. Objetivo: avaliar estudos sobre profilaxia antibiótica na clínica cirúrgica odontológica. Material e métodos: este estudo consiste em uma revisão integrativa da literatura especializada acerca do emprego de fármacos para a profilaxia antibiótica no âmbito da clínica odontológica. Para isso, foi utilizada a base de dados do PubMed na busca de artigos sobre o tema, por meio dos termos "Antibiotic prophylaxis; Dental clinic; Dental surgery; Dentistry", limitando estudos publicados entre 2010 e 2020. Resultados e discussão: foram encontrados 784 artigos e, após a aplicação dos critérios de elegibilidade, 17 artigos compuseram a amostra final da revisão. Os resultados dos artigos apontam para uma alta adesão da profilaxia antibiótica na Odontologia. Conclusões: dentre os antimicrobianos, a amoxicilina isolada e combinada com o clavulanato de potássio é eficaz na prevenção de infecção pós-extração de terceiros molares retidos, mesmo que a amoxicilina com clavulanato produzam mais desconforto gastrointestinal.

Descritores: Antibioticoprofilaxia; Clínicas Odontológicas; Cirurgia Bucal; Odontologia.

\section{Abstract}

Introduction: bacterial involvement is one of the main causes of infections in the head and neck region. For this reason, the therapeutic approach with antimicrobials is recurrent in the field of Dentistry, just as it is quite common to use these drugs as a prophylactic therapeutic mechanism to combat possible systemic infections in the pre and postoperative period. Objective: to evaluate studies on antibiotic prophylaxis in dental surgery clinic. Material and methods: this study consists of an integrative review of the specialized literature on the use of drugs for antibiotic prophylaxis in the scope of dental clinic. For that, the PubMed database was used to search for articles on the topic, using the terms "Antibiotic prophylaxis; Dental clinic; Dental surgery; Dentistry", limiting studies published between 2010 and 2020. Results and discussion: 784 articles were found and, after applying the eligibility criteria, 17 articles made up the final sample of the review. The results of the articles point to a high adherence to antibiotic prophylaxis in Dentistry. Conclusions: among antimicrobials, amoxicillin alone and combined with potassium clavulanate is effective in preventing post-extraction infection of retained third molars, even though amoxicillin with clavulanate produces more gastrointestinal discomfort.

Descriptors: Antibiotic Prophylaxis; Dental Clinics; Dental Surgery; Dentistry.

\section{Resumen}

Introducción: la afectación bacteriana es una de las principales causas de infecciones en la región de la cabeza y el cuello. Por ello, el abordaje terapéutico con antimicrobianos es recurrente en el campo de la Odontología, así como es bastante común utilizar estos fármacos como mecanismo terapéutico profiláctico para combatir posibles infecciones sistémicas en el período pre y postoperatorio. Objetivo: evaluar estudios sobre profilaxis antibiótica en clínica de cirugía dental. Material y métodos: este estudio consiste en una revisión integradora de la literatura especializada sobre el uso de fármacos para la profilaxis antibiótica en el ámbito de la clínica dental. Para ello, se utilizó la base de datos PubMed para la búsqueda de artículos sobre el tema, utilizando los términos "Profilaxis antibiótica; Clínica dental; Cirugía dental; Odontología", limitando los estudios publicados entre 2010 y 2020. Resultados y discusión: se encontraron 784 artículos y, luego de aplicar los criterios de elegibilidad, 17 artículos conformaron la muestra final de la revisión. Los resultados de los artículos apuntan a una alta adherencia a la profilaxis antibiótica en Odontología. Conclusiones: entre los antimicrobianos, la amoxicilina sola y combinada con clavulanato de potasio es eficaz para prevenir la infección posextracción de los terceros molares retenidos, aunque la amoxicilina con clavulanato produce más molestias gastrointestinales.

Descriptores: Profilaxis Antibiótica; Clínicas Odontológicas; Cirugía Bucal; Odontología.

INTRODUÇÃO

Devido à diversidade de espécies presentes na microbiota bucal, as infecções bacterianas são uma das principais causas para o desenvolvimento de afecções purulentas na região de cabeça e pescoço ${ }^{1}$. Como métodos terapêuticos, os fármacos antimicrobianos são um dos principais medicamentos administrados frente a essas infecções, com propriedades bacteriostáticas e bactericidas ${ }^{2}$.

Outrossim, a utilização de antimicrobianos de forma terapêutica é amplamente difundida nas áreas da saúde. $\mathrm{Na}$ Odontologia, corriqueiramente, essa droga é utilizada como mecanismo terapêutico de uso profilático no combate a possíveis infecções sistêmicas no pré e pós operatório ${ }^{3}$. Em razão 
disso, é de suma importância o conhecimento dos mecanismos de ações desses fármacos e a disseminação do conhecimento em todas as modalidades dos cursos odontológicos, sendo imprescindíveis para a prevenção de doenças como otite média aguda e a endocardite bacteriana ${ }^{1,3}$.

Aliado a isso, um dos antibióticos mais utilizados em Odontologia é a amoxicilina, aliado ou não ao clavulanato de potássio ${ }^{2,3}$. Além disso, faz-se necessário aludir à importância dessa associação para o combate da resistência bacteriana para com a penicilina, por apresentar um espectro de ação maior ${ }^{4}$. Ademais, é válido ressaltar que seu uso profilático deve ser monitorado e realizado apenas em situações clínicas nas quais os benefícios superam os riscos, na tentativa de reduzir a resistência bacteriana estimulada pelo uso indiscriminado da antibioticoterapia ${ }^{2}$.

Os resultados de uma revisão sistemática de ensaios clínicos, que buscou investigar a eficácia da Amoxicilina - associada ou não ao ácido clavulânico - em cirurgias de terceiros molares, sugeriram que tanto a amoxicilina quanto a amoxicilina com 0 clavulanato de potássio reduzem de forma significativa o risco de infecção pós-exodontias. Contudo, o uso dessas substâncias deve ser ponderado, devido ao fato de alguns desses estudos clínicos terem observado impactos negativos na diversidade e resistência bacteriana $^{5}$. Dessa forma, este artigo tem por objetivo a realização de uma revisão integrativa de estudos sobre profilaxia antibiótica na clínica cirúrgica odontológica.

MATERIAL E MÉTODO

Trata-se de uma revisão integrativa da literatura especializada, utilizando métodos sistematizados de pesquisa, com base em resultados de estudos científicos previamente publicados envolvendo a temática do emprego de fármacos para a profilaxia antibiótica no âmbito da clínica odontológica.

A pesquisa de revisão foi desenvolvida em seis etapas: definição da pergunta norteadora; processo amostral; categorização dos estudos; análise dos artigos pesquisados; interpretação dos resultados; escrita do artigo de revisão.

Desse modo, a questão condutora da pesquisa partiu da seguinte pergunta: "Qual o melhor fármaco utilizado na clínica cirúrgica odontológica para a profilaxia antibiótica?"

A busca na literatura foi realizada por três pesquisadores entre setembro e outubro de 2020, na base de dados PubMed (U. S. National Library of Medicine), com o objetivo principal de pesquisar e identificar estudos que respondessem à pergunta norteadora desta revisão integrativa.

Nas bases de dados, pesquisou-se pelos artigos científicos por meio da utilização de descritores em inglês $(\mathrm{MeSH})$ : Antibiotic prophylaxis; Dental clinic; Dental surgery; Dentistry; utilizando operador booleano "AND".

A busca pelos artigos limitou os últimos dez anos de publicação (2010-2020). Como critérios de elegibilidade, foram incluídos artigos publicados na língua inglesa - já que a base estudada padroniza artigos dessa língua - que abordaram a temática da profilaxia antibiótica na clínica odontológica. Em contrapartida, foram excluídos os artigos duplicados; estudos que não foram aprovados por um comitê de ética em pesquisa; artigos de revisão sistemática, sistematizada, integrativa e meta-análise; estudos não relacionados à área odontológica.

Inicialmente, foram identificados os artigos pelos títulos e resumos. Aqueles que responderam aos objetivos da presente revisão, foram lidos na íntegra, de modo a compor a amostra. Posteriormente, o conjunto de dados foi tabulado de acordo com os seguintes tópicos: Autor/ano; Periódico de publicação; Objetivo; Amostra e Resultados/conclusão. RESULTADOS

A pesquisa pelos artigos científicos voltados para a temática do estudo totalizou, em primeiro momento, 784 artigos. Após aplicados os critérios de elegibilidade e excluídos os artigos duplicados, 17 artigos compuseram a amostra final da revisão (Figura 1).

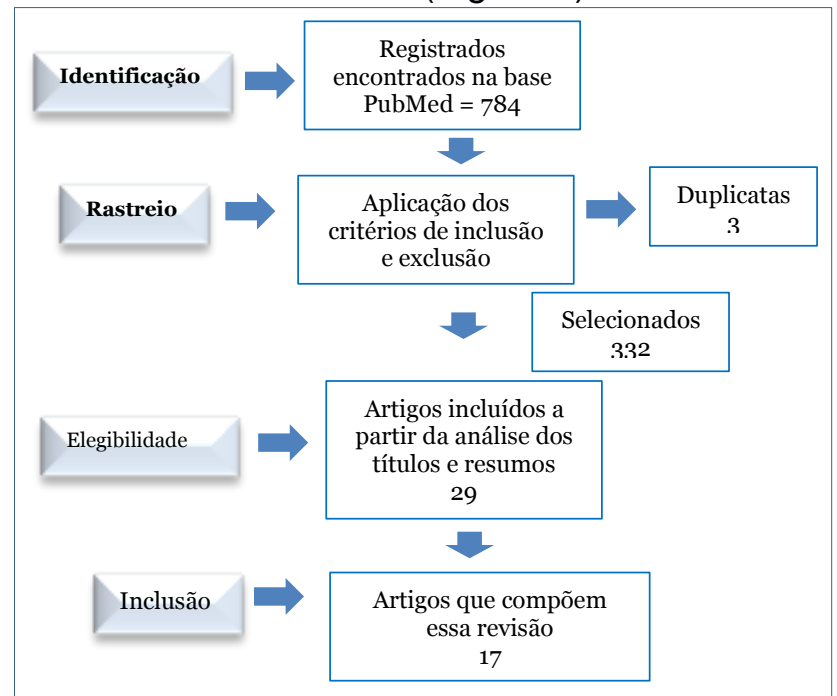

Figura 1: Fluxograma das etapas de seleção de artigos que compuseram a revisão sistematizada.

Os artigos que constituíram a base para o arcabouço teórico da presente pesquisa foram tabulados e organizados conforme os tópicos julgados essenciais para o melhor entendimento acerca da pergunta norteadora (Tabela 1). 
Tabela 1. Artigos selecionados para o estudo

\section{Hafner et al. 6 , 2019}

Períódico $\quad$ Int J Oral Maxillofac Sur

Objetivo do estudo infecciosa (EI) são definidos em hospitais e ambulatórios de infecciosa (EI) são definiclos

Uma pesquisa foi enviada a 80 cirurgiões que chefiam

Amostra

departamentos de cirurgia oral e maxilofacial na Alemanha.

Aproximadamente dois terços dos entrevistados

Resultados/Conclusão prescreveram 10-99 tratamentos para profilaxia de IE por ano, enquanto o terço restante tem mais de 100 prescrições por ano.

Marttila et al.7, 2020

Períódico $\mid$ Acta Odontol Scand

Avaliar a eficácia da profilaxia antibiótica em dose única na prevenção de bacte-riemia após exodontias em um serviço.

Amostra $5^{0}$ pacientes submetidos a extrações dentárias foram A maioria (76\%) recebeu amoxicilina oral profilática ou ampicilina intravenosa, $12 \%$ receberam clindamicina e $12 \%$

Resultados/Conclusão não receberam profilaxia.

Kashani et al. ${ }^{8}, 2019$

Períódico $\quad$ Clin Implant Dent Relat Res.

Comparar as taxas de falha do implante precoce em duas coortes de pacientes diferentes: um grupo recebendo uma única dose de antibióticos pré-operatórios e um grupo que não recebeu antibióticos, antes da cirurgia de implante. Um total de 447 pacientes receberam 963 implantes foram incluídos no estudo. Destes, 223 pacientes (535 implantes)

Amostra pertenciam ao grupo $\mathrm{AB}$ e 224 pacientes (428 implantes) ao grupo noAB.

Doze implantes falharam em 11 pacientes para o grupo $\mathrm{AB}$, e 32 implantes falharam em 29 pacientes para o grupo no $\mathrm{AB}$. Antibióticos pré-operatórios, grupo $\mathrm{AB}$, tiveram falha de implante significativamente menor em $2,2 \%$ em comparação com $7,5 \%$ no grupo noAB

\section{Resultados/Conclusão}

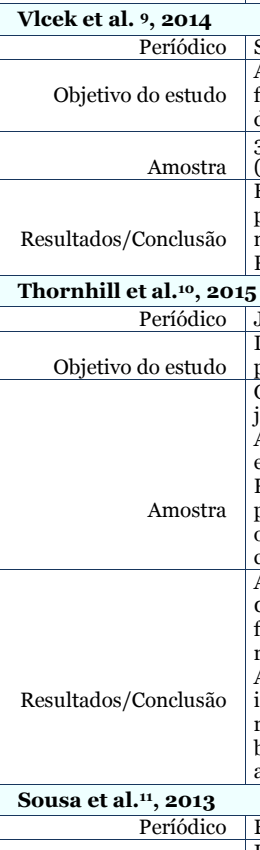

Swiss Dent J foco no uso de antibióticos na remoção cirúrgica profilática de dentes do siso.

3.288 dentistas que são membros da Swiss Dental Society (SSO), representando quase todos os dentistas na Suíça. Foi obtida uma taxa de resposta de $55 \% .52 \%$ dos dentistas prescreveram amoxicilina em uma dose de $750 \mathrm{mg}$. Na maioria das vezes, foram prescritas três doses diárias (47\%). Regime pós-operatório foi prescrito por $54,4 \%$ dos dentistas. J Antimicrob Chemother

dentificar a incidência e a natureza das reações adversas à profilaxia com amoxicilina e clindamicina para prevenir a EI. Obteve-se dados de prescrição de AP para a Inglaterra de janeiro de 2004 a março de 2014 da NHS Business Services Authority, e dados de reação adversa a medicamentos do esquema de relatório de cartão amarelo da Agência Reguladora de Medicamentos e Produtos de Saúde par prescrições do protocolo padrão de AP de um único $3 \mathrm{~g}$ dose oral de amoxicilina ou uma dose oral única de $600 \mathrm{mg}$ de clindamicina para alérgicos à penicilina.

A taxa de reação adversa relatada para a amoxicilina AP foi de o reações fatais / milhão de prescrições e 22,62 reações não fatais / milhão de prescriç̃os. Para a clindamicina, foram 13 reações fatais e 149 reações não fatais / milhão de prescricões. A maioria das reações adversas à droga da clindamicina foram A maioria das reaçôes adversas a droga da clindamicina foram infecçoes por Clostridium difficile. As taxas de notificação de reaçoses adversas a medicamentos de AP na Inglaterra foram

\section{\begin{tabular}{|l|l} 
Períódico & Eur J Clin Microbiol Infect Dis \\
\hline & Identicar a microbiota de canar
\end{tabular}}

Identificar a microbiota de canais radiculares com absces-sos

Objetivo do estudo espécies de bactérias a antibióticos. investigando a produção de $\beta$-lactamase.

60 canais radi-culares foram investigados microbiológicamente. Um total de 287 cepas bacterianas diferentes foram

Amostra recuperadas, incluindo 201 anaeróbios es-tritos. Os anaeróbios isolados mais estritos foram A. prevotii, P. micra e F. necrophorum.

Todos os microrganismos testados foram sensíveis à benzilpenicilina, amoxicilina, amoxicilina + clavulanato,

Resultados/Conclusão cefaclor e clindamicina não produzindo $\beta$-lactamase.

\section{Fadare et al. ${ }^{12}, 2017$}

\section{Períódico Acta Odontol Scand}

Objetivo do estudo

Avaliar os padrões de medicamentos prescritos para pacientes ambulatoriais atendidos em uma clínica odontológica de hospital na Nigéria.

Amostra Prontuários médicos de pacientes atendidos em um hospital universitário da Nigéria.

Entre os antimicrobianos, a amoxicilina (564; 95,1\%) isolada ou associada ao ácido clavulânico foi a mais

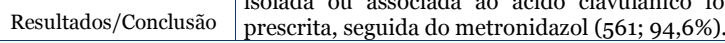

Posse et al.13 (2016).

Períódico Oxford University Press em nome da British Society for Antimicrobial Chemotherapy

Objetivo do estudo $\quad$ Avaliar a eficácia de quatro regi-mes antimi-crobianos para a prevenção de bacteriemia após extrações dentárias.

Amostra 266 adultos que necessitaram de extrações dentárias.

A incidência de bacteriemia nos grupos controle, amoxicilina / clavulanato (96\%), amoxicilina (50\%), clindamicina (87\%) e azitromicina (81\%).
Tabela 1 (continuação). Artigos selecionados para o estudo Iglesias-Martín et al. ${ }^{14,}, 2014$ Períódico Journal section: Oral Surgery

Objetivo do estudo $\begin{aligned} & \text { Comparar o } \\ & \text { clavulanato }\end{aligned}$ (875 / 125mg) após extração de terceiros mo-lares retidos para preven-ção de complicaçõ-es infeccio-sas.

Amostra 546 pacientes atendidos para remoção de um terceiro molar retido e divididos em dois grupos: Grupo 1 - grupo amoxicilina e clavunato $(875 / 125$

grupo amoxicilina $(1 \mathrm{~g})(\mathrm{n}=289)$.

Resultados/Conclusão $\quad \begin{aligned} & \text { a fre os dois grupos. Os resultados do nos-so estudo mostram } \\ & \text { entran }\end{aligned}$ que os dois grupos. Os resultados do dilina estudo mostram que o uso de amoxicinna (1g) e amoxicilina e clavunato (875/ $125 \mathrm{mg}$ ) é simlar e eficaz na preven-ção de infecção após a clavunato (875 125mg) produzem mais desconforto

Sisalli et al. ${ }^{15}, 2012$

Períódico International Jornal of Immunopathology and Pharmacology Comparar a eficácia e os efeitos colate-rais de dois medicamentos diferentes,

Objetivo do estudo amoxicilina e ácido clavulâ-nico ceftazidi-ma, usados como profila-xia antibiótica na extração cirúrgica

de terceiros molares.

107 pacientes com terceiro molar retido foram selecionados e divididos con dois

Amostra foram administrados ao grupo 1 e ceftazidima ao grupo 2 por cinco dias após a cirurgia e observado o pós-operatório.

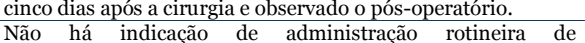
Não há indicação de administração rotineira de
antibioticoterapia profilática de segunda escolha

antibioticoterapia profilática de segunda escolha
intramuscular (ceftazidima) em caso de exodontia cirúrgica do terceiro molar. al.16, 2014

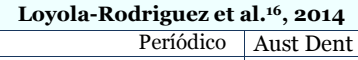

Identificar bactérias de infecç̃es dentárias e determinar resistência aos antibióticos usados no atendimento odontológico na dentição decídua.

Objetivo do estudo resiste 60 crianças que se apresentaram para tratamento

Amostra odontológico por infecções dentárias ativas na dentição decídua.

A clindamicina em ambas as concentrações testadas (8 $\mu \mathrm{g} / \mathrm{ml} \mathrm{e} 16 \mu \mathrm{g} / \mathrm{ml}$ ) apresentou a maior resistência bacteriana $(85,9 \%)$, seguida pela amoxicilina $(43,7 \%)$ A-CA (12,0\%). Este estudo demonstrou que A-CA exibiu a menor resistência bacteriana para isolados clínicos em infecções da dentição decídua.

El-Kholey et al. ${ }^{17}, 2018$

Períódico J Antimicrob Chemother

\begin{tabular}{l|l} 
Identificar a incidência e a natureza das reações adversas \\
Ora
\end{tabular} profilaxia com amoxicilina e clindamicina para prevenir a EI. Obteve-se dados de prescrição de AP para a Inglaterra de Obteve-se dados de prescrição de AP para a Inglaterra de
janeiro de 2004 a março de 2014 da NHS Business Services janeiro de 2004 a março de 2014 da NHS Business Services esquema de relatório de cartão amarelo da Agência Reguladora de Medicamentos e Produtos de Saúde para oral de amoxicilina ou uma dose oral única de $600 \mathrm{mg}$ de
clindamicina para alérgicos à penicilina.

A taxa de reação adversa relatada para a amoxicilina AP foi de o reações fatais / milhão de prescrições e 22,62 reações não fatais / milhão de prescrições. Para a clindamicina, foram 13 reações fatais e 149 reações não fatais / milhão de prescrições. A maioria das reações adversas à droga da clindamicina foran

Resultados/Conclusão infeccões por Clostridium difficile. As taxas de notificacão de reações adversas a medicamentos de AP na Inglaterra foram baixas, particularmente para amoxicilina, e menores do que as estimativas anteriores.

Shah, Ramola e Nautiyal ${ }^{18}, 2016$

Períódico $\quad$ Natl J Maxillofac Surg

Objetivo do estudo $\quad$ Identificar mi-crorganismos aeróbicos causadores

responsáveis pos fasciais profundos de infecções de cabeça e pescoço e avaliar a resistência aos antibióticos usado no tratamento de tais.

100 pacientes que relataram no ambulatorio e preencheram os critérios de inclusão para estudar a micro-biologia aeróbia e a sensibilidade a antibióticos na infecção do espaço da cabeça e pescoço de origem odontogênica.

A amoxicilina mostrou resistência (48,4\%), em comparação

Resultados/Conclusão com outros antibióticos, como ceftriaxona, carbenicilina, amicacina e imipenem, tiveram sensibilidade significativamente maior. A amoxicilina com ácido clavulânico mostrou $(64,8 \%)$ eficácia para todos os organismos isolados, enquanto a ceftriaxona mostrou $(82,4 \%)$ eficácia e pode ser usada em infecções odontogênicas para microrganismos Gram-positivos e Gram-negativos.

Arteagoitia I et al.19, 201

Períódico $\quad$ Oral Surg Oral Med Oral Pathol Oral Radiol

Objetivo do estudo Determinar o efeito da amoxicilina / ácido clavulânico na prevenção da infecção após a remoção do terceiro molar inferior completamente impactado pelo osso.

Amostra 118 adultos alocados aleatoriamente para placebo $(60$ pacientes) ou tratamento com antibióticos ( 58 pacientes): 2 g de amoxicilina / $125 \mathrm{mg}$ de ácido clavulânico 2 horas antes da cirurgia e pós-operatório duas vezes por dia durante 4 dias. $\begin{array}{ll}\text { Resultados/Conclusão } & \text { Não houve relação entre as variáveis estudadas e infecção. } \\ \text { Não foram relatados eventos adversos graves Nâ há }\end{array}$ Nao foram relatados eventos adversos graves. Nao ha
evidências suficientes para recomendar o uso rotineiro desse evidencias suficientes para
tratamento antibiótico 
Tabela 1 (continuação). Artigos selecionados para o estudo Esen $A^{20}, 2017$ J Istanb Univ Fac Dent Avaliar os efeitos da amoxicilina administrada por via oral isolada ou combinada com ácido clavulânico na frequência de

\begin{tabular}{ll} 
Objetivo do estudo & $\begin{array}{l}\text { complicações pós-operatórias e no conforto dos pacientes } \\
\text { após cirurgia do terceiro molar mandibular. }\end{array}$ \\
\hline
\end{tabular}

\begin{tabular}{ll} 
Objetivo do estudo & $\begin{array}{l}\text { complicações pós-operatórias e no conforto dos pacientes } \\
\text { após cirurgia do terceiro molar mandibular. }\end{array}$ \\
\hline
\end{tabular} ciruria do terceiro molar inferior entre outubro de 2014 e

Amostra dezembro derceiro

A análise das variáveis mostrou que não houve diferenças signifi-cativas entre os Grupos A e AC quanto aos níveis de dor, edema, trismo e escores de QV. Dessa forma, pode-se dor, edena, triste lavin que a a clavilanico poden for termos de conforto do paciente apos a cirurgia do terceiro molar.

Loyola-Rodriguez et al.21, 2018

\begin{tabular}{|c|c|}
\hline Períódico & Acta Odontol Scand \\
\hline Objetivo do estudo & $\begin{array}{l}\text { Determinar e identificar bactérias resistentes a antibióticos } \\
\text { (ARB) de estreptococos orais de } \\
\text { infecções dentárias em adultos e sua associação com idade e } \\
\text { sexo. }\end{array}$ \\
\hline Amostra & $\begin{array}{l}\text { Este estudo transversal incluiu } 59 \text { indivíduos de } 18 \text { a } 62 \text { anos. } \\
\text { Noventa e oito amostras obtidas dos sujeitos foram cultivadas } \\
\text { em placas de ágar contendo antibióticos amoxicilina / ácido } \\
\text { clavulânico (A-CA), clindamicina e moxifloxacina } \\
\text { (concentrações de } 16,32 \text { ou } 64 \mu \mathrm{g} / \mathrm{ml} \text { ). }\end{array}$ \\
\hline Resultados/Conclusão & 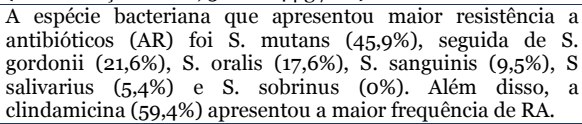 \\
\hline \multicolumn{2}{|l|}{ Sayd et al. ${ }^{22}, 2018$} \\
\hline Períódico & J Korean Assoc Oral Maxillofac Surg \\
\hline Objetivo do estudo & $\begin{array}{l}\text { Investigar os efeitos clínicos do ácido amoxicilina- } \\
\text { clavulânico (50o + 125 mg) com metronidazol 400 mg } \\
\text { administrado três vezes ao dia (Grupo I) versus azitromicina } \\
500 \mathrm{mg} \text { administrado uma vez ao dia e com metronidazol } \\
400 \mathrm{mg} \text { três vezes ao dia (Grupo } \\
\text { II) para a prevenção de infecção pós-operatória após a } \\
\text { remoção cirúrgica do terceiro molar inferior. }\end{array}$ \\
\hline Amostra & $\begin{array}{l}\text { Os pacientes que compareceram ao Departamento de Cirurgia } \\
\text { Bucomaxilofacial entre fevereiro de } 2015 \text { e janeiro de } 2017 \\
\text { para remoção do terceiro molar inferior foram selecionados, e } \\
108 \text { pacientes foram selecionados. }\end{array}$ \\
\hline Resultados/Conclusão & $\begin{array}{l}\text { O Grupo II teve menor incidência de infecção de sítio } \\
\text { cirúrgico, mas sem significância estatística. Embora ambos os } \\
\text { tratamentos sejam usados rotineiramente após a remoção do } \\
\text { terceiro molar inferior, nenhum é significativamente melhor } \\
\text { do que o outro. }\end{array}$ \\
\hline
\end{tabular}

DISCUSSÃO

O presente estudo buscou, através de uma revisão sistematizada, mostrar a eficácia da profilaxia antibiótica na terapêutica odontológica, onde em procedimentos específicos e gerais presentes nos artigos utilizados se obteve, de modo geral, a confirmação da importância e eficácia do uso da antibioticoterapia.

De acordo com os resultados obtidos no estudo de Zanatta et al. ${ }^{23}$, $89 \%$ dos Cirurgiões Dentistas utilizavam profilaxia pré-operatória e $100 \%$ prescreviam no pós-operatório em procedimentos cirúrgicos. Já no estudo de Vleck et al. ${ }^{9}$, um total de $52 \%$ dos dentistas prescreveu antibiótico pré-operatório e 47\% pós-operatório. Mesmo diante dessa divergência estatística, cabe ressaltar que os Cirurgiões Dentistas continuam fazendo uso da antibioticoterapia em procedimentos cirúrgicos, tanto de forma preventiva como no tratamento de eventos pós-cirúrgicos.

Hafner et al. ${ }^{6}$ obtiveram como principal conclusão em seu estudo que a maioria dos profissionais da odontologia prescrevem antibióticos sem seguir os padrões de segurança para que não ocorra a resistência bacteriana e dessa forma fazem uso excessivo dos antibióticos em procedimentos invasivos e não invasivos como por exemplo a injeção de anestésico em tecido não infectado.

Já Wilson et al. $^{24}$ defendem que procedimentos como injeção de anestésico através de tecidos não infectado, radiografias dentárias e instalação de próteses dentárias não necessitam de profilaxia antibiótica. Por outro lado, Oliveira et al. ${ }^{25}$ especificaram que nos pacientes com alto risco ao desenvolvimento de endocardite bacteriana é indicada a profilaxia antibiótica nos procedimentos tais como, anestesia local intraligamentar, ortodontia inicial e profilaxia com possível sangramento.

No entanto, é de extrema importância a construção de um protocolo de antibioticoterapia profilática em cirurgia oral e que a escolha dos antibióticos a serem usados requer critérios bem definidos ${ }^{26}$.

O estudo de Vasconcelos e Polônia ${ }^{26}$ traz o regime de profilaxia antibiótica elencado em um quadro que mostra a amoxicilina na concentração de $2 \mathrm{~g}$ em adultos e $50 \mathrm{mg} / \mathrm{kg}$ em criança, ambos com administração por via oral, concordando com os resultados do estudo de Marttila et al. ${ }^{7}$, no qual mostra que $76 \%$ dos indivíduos receberam amoxicilina por via oral de forma profilática. Em paralelo, segundo Wilson et al. ${ }^{24}$, a amoxicilina começou a ser utilizada na profilaxia antibiótica em 1990 na concentração de $2 \mathrm{~g}$ por via oral uma hora antes do procedimento.

O estudo de Kashani et al. ${ }^{8}$ mostrou evidências da antibioticoterapia no sucesso das cirurgias de implantes dentários. Nesse estudo, seus resultados demonstraram um maior risco de falha dos implantes no grupo de pacientes que não recebeu profilaxia antibiótica. Por outro lado, apesar de Schlickman ${ }^{27}$ apontar a inexistência de um consenso entre os implantodontistas sobre o uso de antibióticos como medida preventiva, outros autores divergem sobre o tema. Ahmad e Saad" ${ }^{28}$, por meio de uma revisão sistemática da literatura, comprovaram a eficácia da antibioticoprofilaxia quando analisaram os resultados em pacientes que realizaram ou não a profilaxia antibiótica, cujos resultados estimaram $96,5 \%$ de sucesso para os que receberam antibióticos e $92 \%$ para os que não receberam antibióticos.

Quanto ao uso da antibioticoterapia em endodontia, o estudo de Sousa et al. ${ }^{11}$ mostrou que a microbiota nos canais radiculares foi sensível a diversos antibióticos, porém destacase a amoxicilina associada ou não ao clavulanato de potássio seguida da clindamicina para bactérias não produtoras de betalactamase. Di Santi ${ }^{29}$ concorda com o fato anteriormente exposto, ao apontar a importância 
do uso dos antibióticos no tratamento das infecções endodônticas e afirma que as penicilinas continuam sendo os antibióticos de escolha na Odontologia, em particular a amoxicilina. Em casos de reações alérgicas, deve-se fazer opção pela clindamicina ou azitromicina.

Como determinação e identificação de bactérias resistentes a antibióticos contra estreptococos orais provenientes de infecções odontológicas, Loyola-Rodriguez et al. ${ }^{21}$ documentaram que a espécie bacteriana que apresentou maior resistência a antibióticos foi, respectivamente, $S$. mutans, seguida de $S$. gordonii, S. oralis, $S$. sanguinis, $S$ salivarius e $S$. sobrinus. Além disso, a clindamicina apresentou, nesse estudo, a maior frequência de reações alérgicas.

Outrossim, conforme o estudo de Sayd et $\mathrm{al}^{22}$, ao analisar os efeitos clínicos da amoxicilina associada ao ácido clavulânico (500 + $125 \mathrm{mg}$ ) com metronidazol $400 \mathrm{mg}$ administrado três vezes ao dia (Grupo I) e azitromicina $500 \mathrm{mg}$ administrado uma vez ao dia com metronidazol $400 \mathrm{mg}$ três vezes ao dia (Grupo II) como profilaxia antibiótica para a remoção cirúrgica do terceiro molar inferior, observaram que o Grupo II obteve menor incidência de infecção no sítio cirúrgico, mas sem significância estatística. Desse modo, concluíram que, dos dois protocolos apresentados, nenhum é significativamente melhor do que o outro.

Cabe ressaltar ainda que, durante a pesquisa dos artigos científicos sobre a temática do estudo, optou-se pela base de dados PubMed devido a uma maior concentração de artigos que atendiam ao objetivo desta revisão. Dessa forma, sugere-se o desenvolvimento de pesquisas - tanto com delineamentos epidemiológicos quanto clínicas - que busquem aprofundar os estudos sobre a antibioticoprofilaxia na Odontologia.

CONCLUSÃO

Com o intuito de expor a eficácia da profilaxia antibiótica na terapêutica odontológica, conclui-se, portanto, que a maioria dos profissionais da odontologia prescrevem antibióticos sem seguir os padrões de segurança, promovendo o uso excessivo dos antibióticos em procedimentos invasivos e não invasivos. Além disso, as penicilinas continuam sendo os antibióticos de escolha na Odontologia, em particular a amoxicilina. Em casos de reações alérgicas, deve-se fazer opção pela clindamicina ou azitromicina. Entre os antimicrobianos, a amoxicilina isolada ou associada ao ácido clavulânico foi a mais prescrita, seguida do metronidazol. Ademais, o uso de amoxicilina e amoxicilina com clavulanato de potássio é similar e eficaz na prevenção de infecção após a extração do terceiro molar retido, porém foi documentado que a amoxicilina e clavulanato produziram mais desconforto gastrointestinal.

REFERÊNCIAS

1. Bogacz M, Morawiec T, Smieszek-Wilczewska J, Janowska-Bogacz K, Bubitek-Bogacz A, Roj $\mathrm{R}$, Pinocy $\mathrm{K}$ et al. Evaluation of Drug Susceptibility of Microorganisms in Odontogenic Inflammations and Dental Surgery Procedures Performed on an Outpatient Basis Biomed Res Int. 2019:2010453.

2. Whalen K, Finkel R, Panavelil TA. Farmacologia Ilustrada. 6. ed. Porto Alegre: Artmed; 2016.

3. Zeng BS, Lin SY, Tu YK, Wu YC, Stubbs B, Liang CS et al. Prevention of Postdental Procedure Bacteremia: A Network Metaanalysis J Dent Res. 2019;98(11):1204-10.

4. Piltcher OB, Kosugi EM, Sakano E, Mion O, Testa JRG, Romano FR et al. Como evitar o uso inadequado de antibióticos nas infecções de vias aéreas superiores? Posição de um painel de especialistas. Braz J Otorhinolaryngol. 2018;84(3):265-79.

5. Menon RK, Gopinath D, Li KY, Leung YY, Botelho MG. Does the use of amoxicillin/amoxicillin-clavulanic acid in third molar surgery reduce the risk of postoperative infection? A systematic review with metaanalysis. Int J Oral Maxillofac Surg. 2019; 48(2):263-273.

6. Hafner S, Albittar M, Abdel-Kahaar E, Zolk O. Antibiotic prophylaxis of infective endocarditisin oral and maxillofacial surgery: incomplete implementation of guidelinesin everyday clinical practice. Int J Oral Maxillofac Surg. 2019; 49(4):22-8.

7. Marttila E, Grönholm L, Saloniemi M, Rautemaa-Richardson R. Prevalence of bacteraemia following dental extraction efficacy of the prophylactic use of amoxicillin and clindamycin, Acta Odontol Scand. 2021;79(1):25-30.

8. Kashani $\mathrm{H}$, Hilon J, Rasoul MH, Friberg B. Influence of a single preoperative dose of antibiotics on the early implant failure rate. $A$ randomized clinical trial. Clin Implant Dent Relat Res. 2019;21(2):278-83.

9. Vlcek D, Razavi A, Kutten-Berger J. Antibiotics in third molar surgery. Swiss Dent J. 2014; 124(3):294-302.

10. Thornhill MH, Dayer MJ, Prendergast $B$, Baddour LM, Jones S, Lockhart PB. Incidence and nature of adverse reactions to antibiotics 
used as endocarditis prophylaxis. J Antimicrob Chemother 2015;70(8):2382-88.

11. Sousa ELR, Gomes BPFA, Jaciento RC, Zaia AA, Ferraz CCR. Microbiological profile and antimicrobial susceptibility pattern of infected root canals associated with periapical abscesses. Eur J Clin Microbiol Infect Dis, 2013;32(4):573-580.

12. Fadare JO, Oshikoya KA, Obimakinde OS, Sijuade AO, Afolayan JM, Adeleke AA et al. Patterns of drugs prescribed for dental outpatients in Nigeria: findings and implications. Acta Odontol Scand. 2017;75(7):496-506.

13. Posse JL, Fernández MA, Feijoo JF, Henríquez JM, Lockhart PB, Chu VH et al. Intravenous amoxicillin/clavulanate for the prevention of bacteraemia following dental procedures: a randomized clinical trial. J Antimicrob Chemother. 2016;71(7):2022-30.

14. Iglesias-Martín F, García-Perla-García A, Yañez-Vico R, Aced-Jiménez E, ArjonaGerveno E, González-Padilla JD et al. Comparative trial between the use of amoxicillin and amoxi- Comparative trial between the use of amoxicillin and amoxi- Comparative trial between the use of amoxicillin and amoxicillin clavulanate in the removal of third molars. Med Oral Patol Oral Cir Bucal. 2014;19(6):e612-5.

15. Sisalli U, Lalli C, Cerone L, Maida S, Manzoli L, Serra E et al. Amoxicillin and clavulanic acid vs ceftazidime in the surgical extraction of impacted third molar: a comparative study. Int $\mathrm{J}$ Immunopathol Pharmacol. 2012;25(3):771-74.

16. Loyola-Rodriguez JP, Garia-Cortes JO, Martinez-Martinez RE, Patiño-Marin N, Martinez-Castañon GAZavala-Alonso NV. Molecular identification and antibiotic resistant bacteria isolated from primary dentition infections. Aust Dent J. 2014;59(4):497-503.

17. El-Kholey KE, Wali O, Elkomy A, Almozayen A. Pattern of Antibiotic Prescription for Oral Implant Treatment Among Dentists in Saudi Arabia. Implant Dent. 2018; 27(3):317-23.

18. Shah A, Ramola V, Nautiyal V. Aerobic microbiology and culture sensitivity of head and neck space infection of odontogenic origin. Natl J Maxillofac Surg. 2016;7(1):56-61.

19. Arteagoitia I, Ramos E, Santamaria G Barbier L, Alvarez J, Santamaria J. Amoxicillin/clavulanic acid 2000/125 mg to prevent complications due to infection following completely bone-impacted lower third molar removal: a clinical trial, Oral Surg Oral Med Oral Pathol Oral Radiol. 2015;119(1):8-16.

20. Esen A. The effects of amoxicillin with or without clavulanic acid on the postoperative complaints after third molar surgery: a retrospective chart análisis. J Istanbul Univ Fac Dent. 2017;51(2):1-6.
21.Loyola-Rodriguez JP, Ponce-Diaz ME, LoyolaLevya A, Garcia-Cortes JO, Medina-Solis CE, Contreras-Ramire AA. Determination and identification of antibiotic-resistant oral streptococci isolated from active dental infections in adults. Acta Odontol Scand. 2018; 76(4):229-35.

22. Sayd S, Vyloppilli S, Kumar K, Subash P, Kumar N, Raseel S. Comparison of the efficacy of amoxicillin-clavulanic acid with metronidazole to azithromycin with metronidazole after surgical removal of impacted lower third molar to prevent infection. J Korean Assoc Oral Maxillofac Surg, 2018;44(3):103-6.

23.Zanatta FB, Richter EA, Pedroso ARS, Rosing CK. Condutas clínicas na utilização de antibióticos em exodontias. RGO Rev gaúch odontol. 2011;59(2):171-77.

24. Wilson W, Taubert KA, Gewitz M, Lockhart PB, Baddour LM, Levison $M$ et al. Prevention of infective endocarditis: guidelines from the American Heart Association. J Am Dent Assoc. 2008;139(Suppl):3S-24S.

25. Oliveira ILM, Ferreira ACA, Mangueira LFB, Farias IAP. Antimicrobianos de uso odontológico: informação para uma boa prática. Odontol Clín.-Cient. 2011;10(3):217-20.

26. Vasconcelos C, Polônia AJ. Profilaxia antibiotica. Cadernos de Saúde. 2010;3(Esp): 101-6.

27. Schlickmann, A. Profilaxia antibiótica em implantodontia: revisão de literatura [monografia]. Tubarão: Curso de Odontologia, Universidade do Sul de Santa Catarina; 2019.

28. Ahmad N, Saad N. Effects of antibiotics on dental implants: a review. J Clin Med Res. 2012;4(1):1- 6 .

29. Di Santi BT, Ribeiro MB, Endo MS, Gomes BPFA. Avaliação da suscetibilidade antimicrobiana de bactérias anaeróbias facultativas isoladas de canais radiculares de dentes com insucesso endodôntico frente aos antibióticos de uso sistêmico. Rev Odontol UNESP. 2015;44(4):200-6.

\section{CONFLITO DE INTERESSES}

Os autores declaram não haver conflitos de interesse

\section{AUTOR PARA CORRESPONDÊNCIA}

\section{Gustavo Correia Basto da Silva}

Av. Joaquim Caroca, Universitário, 58429-120 Campina Grande - PB, Brasil

E-mail: gugacorreiaa@gmail.com 